\title{
Circulating Tumor Cells Correlate with Clinicopathological Features and Outcomes in Differentiated Thyroid Cancer
}

\author{
Zhong-Ling Qiu Wei-Jun Wei Zhen-Kui Sun Chen-Tian Shen \\ Hong-Jun Song Xin-Yun Zhang Guo-Qiang Zhang Xiao-Yue Chen \\ Quan-Yong Luo
}

Department of Nuclear Medicine, Shanghai Jiao Tong University Affiliated Sixth People's Hospital, Shanghai, P. R. China

\section{Key Words}

Circulating tumor cells - Differentiated thyroid cancer - Refractory to radioiodine - Distant metastases $• \mathrm{NE}$-iFISH

\begin{abstract}
Background/Aims: As biomarkers, circulating tumor cells (CTCS) from solid tumors can predict metastases and prognoses, and help monitor treatment efficacy. However, conventional CellSearch methods have low sensitivity to differentiated thyroid cancer (DTC) CTCs. In this study, for the first time, we used negative enriching (NE) immunofluorescence-in situ hybridization (iFISH) of chromosome 8 to capture and identify CTCs in DTC patients; and investigated how CTCs correlate with clinicopathological factors and prognosis in DTC patients with distant metastases (DM). Methods: In this prospective study, we enrolled 72 patients with DTC before they underwent ${ }^{131}$ I treatment, and 30 healthy controls $(\mathrm{HC})$. Their CTCs were measured in $7.5 \mathrm{ml}$ peripheral blood using the NE-iFISH technique. CTC was defined by the aneuploidy. Results: We detected CTCs in 62 (86.1\%) of the 72 subjects with DTC. The mean number of CTCs in patients with DTC with DM $\left(\mathrm{DM}^{+}\right)$was significantly higher than in the HC group $(P<0.001)$ and DTC patients without DM ( $\left.\mathrm{DM}^{-} ; P=0.0016\right)$. We found $\mathrm{CTCs} \geq 5$ was significantly associated with DM+ DTC ( $P=0.009$; sensitivity: $64.3 \%$; specificity: $83.8 \%)$; CTCs $\geq 7$ was related to poor response to ${ }^{131}$ I treatment (sensitivity: $73.7 \%$; specificity: $69.6 \%$ ), and was also associated with worse prognosis in DM+ DTC $(P<0.001)$. Conclusion: We found CTCs $\geq$ 5 to be a potential predictive index for DM+ DTC; and CTCs $\geq 7$ as a possible indicator of poor response to ${ }^{131}$ I treatment and worse prognosis in $\mathrm{DM}^{+}$DTC.
\end{abstract}

Zhong-Ling Qiu, Wei-Jun Wei and Zhen-Kui Sun contributed equally to this work. 


\title{
Introduction
}

Although the incidence of differentiated thyroid cancer (DTC) has increased worldwide, it has an excellent prognosis, with a 90\% 10-year overall survival rate [1] However, for DTC patients with distant metastases (DMs), quality of life and survival time are seriously diminished [2, 3]. DTC with DM is commonly treated with radioiodine $\left({ }^{131} \mathrm{I}\right)$, but about $30 \%$ of such patients have radioiodine-refractory DTC (RR-DTC) [4], which has a 10-year survival rate of only $\sim 10 \%$ from DM detection [5]. Obviously, patients with RR-DTC do not significantly benefit from ${ }^{131}$ I treatment, and may suffer adverse effects from high serum TSH stimulation after thyroxin withdrawal [6]. Although detection of serum thyroglobulin (Tg) levels was a reliable predictor of DTC DMs, this method is limited by metastatic lesions' ability to release detectable amounts of $\mathrm{Tg}$, loss of the ability of secreting Tg with preserved capability of ${ }^{131} \mathrm{I}$ trapping, structural changes in $\mathrm{Tg}$, or Tg level decreased by elevated circulating Tg antibodies (TgAb) [7, 8] ]. Also, Tg levels do not predict RR-DTC [9] . Therefore, tumor markers that can help detect DTC DMs and predict RR-DTC are sorely needed.

Circulating tumor cells (CTCs) are rare tumor cells that escape from solid tumors, travel into peripheral blood circulation, and seed DMs. They have been widely used for early DM detection, monitoring prognoses and treatment efficacy, and risk stratification for some solid tumors $[10,11]$. The CellSearch system is the most widely used assay for CTCs, and depends on expression of CTC-surface epithelial cell adhesion molecule (EpCAM) [12]. However, the CellSearch system has a low detection rate for DTC CTCs, probably due to their low EpCAM expression during epithelial-mesenchymal transition (EMT) [13]. Negative enrichment (NE) combined with immunofluorescence and in situ chromosomal hybridization (NE-iFISH) is reportedly effective in detecting CTCs from gastric or pancreatic cancers [14] [15], but its use in detecting CTCs from metastatic DTC has not been reported.

We hypothesized that CTCs in DTC patients are associated with DMs, response to ${ }^{131} \mathrm{I}$ treatment, and prognosis. In this study, we detected the numbers of CTCs in DTC patients using the NE-iFISH and explored whether CTC levels were related to clinicopathological factors or outcomes in patients with $\mathrm{DM}^{+}$DTC.

\section{Materials and Methods}

\author{
Ethical approval \\ This study was performed in accordance with the ethical standards of our hospital.
}

\section{Informed consent}

Informed consents were obtained from all individual participants was used in the study.

\section{Patients}

The study was performed at the Shanghai Sixth People's Hospital, a major ${ }^{131}$ I treatment center in China, and was approved by its ethics committee. We enrolled 42 patients with $\mathrm{DM}^{+}$DTC treated between August 2014 and August 2017, and 30 patients with DM- DTC patients treated during August 2017. The inclusion criteria were (a) patients with histologically proven DTC (follicular thyroid cancer [FTC] or papillary thyroid cancer [PTC]); and (b) treatment with total or near-total thyroidectomy and postoperative ${ }^{131}$ I ablation. Patients with histories of other malignancies or other adjuvant therapy were excluded. The DTC patients were classified as having intermediate high risk [16]. We also included 30 healthy volunteers, with no illness or past cancer history, as a healthy control (HC) group. All participants gave informed written consent.

Baseline data were recorded when peripheral blood samples were collected for CTC detection, including age, sex, maximum tumor diameter, DTC pathology, extrathyroidal invasion, numbers of primary tumors, $\mathrm{N}$ stage, serum stimulated thyroglobulin (sTg), and TgAb (Table 1); after each ${ }^{131}$ I therapy and during the follow-up, results of sTg, TgAb, ${ }^{131}$ I whole-body scan ( ${ }^{131} \mathrm{I}$-WBS) combined with SPEC/CT, other medical imaging such as CT and ${ }^{18} \mathrm{~F}-\mathrm{FDG}$ PET/CT, courses ${ }^{131} \mathrm{I}$ treatment, cumulative ${ }^{131} \mathrm{I}$ activity, sites and numbers of DMs and follow-up time were recorded. 


\section{Cellular Physiology Cell Physiol Biochem 2018;48:718-730 \begin{tabular}{c|c|c|} 
DOI: 10.1159/000491898 & $\begin{array}{l}\text { O } 2018 \text { The Author(s). Published by S. Karger AG, Basel } \\
\text { www.karger.com/cpb }\end{array}$
\end{tabular} \\ Qiu et al.: Circulating Tumor Cells in DTC}

Table 1. Patient demographics. Tumor size $(\mathrm{mm})^{*}$ : maximum diameter of tumor; DTC: differentiated thyroid cancer; FTC: follicular thyroid carcinoma; PTC: papillary thyroid carcinoma; DM: distant metastases

\begin{tabular}{|c|c|c|c|c|}
\hline \multirow[b]{2}{*}{ Characteristic } & \multicolumn{3}{|c|}{ NO. of patients } & \multirow[b]{2}{*}{$\begin{array}{c}\text { Healthy } \\
\text { control }(\mathrm{N}=30)\end{array}$} \\
\hline & $\begin{array}{c}\text { All } \\
(\mathrm{N}=72)\end{array}$ & $\begin{array}{l}\text { DTC without } \\
\text { DM }(\mathrm{N}=30)\end{array}$ & $\begin{array}{c}\text { DTC with } \\
\text { DM }(\mathrm{N}=42)\end{array}$ & \\
\hline \multicolumn{5}{|l|}{$\overline{\text { Sex }}$} \\
\hline Male & 31 & 14 & 17 & 11 \\
\hline Female & 41 & 16 & 25 & 19 \\
\hline Mean age at baseline (range) & $\begin{array}{l}44.4(12- \\
71)\end{array}$ & $46.1(16-68)$ & $43.2(12-71)$ & $44.5(23-71)$ \\
\hline Pathological of DTC & & & & _ \\
\hline PTC & 61 & 28 & 33 & - \\
\hline FTC & 11 & 2 & 9 & - \\
\hline Extrathyroidal invasion & & & & - \\
\hline Yes & 31 & 9 & 22 & - \\
\hline No & 41 & 21 & 20 & - \\
\hline \multicolumn{5}{|l|}{ Multifocality } \\
\hline 1 & 51 & 20 & 31 & _- \\
\hline$>1$ & 21 & 10 & 11 & - \\
\hline \multicolumn{5}{|l|}{ Tumor size $(\mathrm{mm})^{*}$} \\
\hline$\leq 30$ & 43 & 27 & 16 & _ \\
\hline$>30$ & 29 & 3 & 26 & _- \\
\hline \multicolumn{5}{|l|}{$\mathrm{N}$ stage } \\
\hline No & 19 & 9 & 10 & _ \\
\hline N1a & 15 & 10 & 5 & - \\
\hline N1b & 22 & 8 & 14 & - \\
\hline $\mathrm{Nx}$ & 16 & 3 & 13 & _- \\
\hline Mean sTg level prior to ${ }^{131}$ I & 1431 & 59 & $2412(41.4-$ & \\
\hline Treatment, ng/ml(range) & $17221)$ & $(1.3-532.6)$ & 17221) & - \\
\hline $\begin{array}{l}\text { Mean TgAb level prior to }{ }^{131} \mathrm{I} \\
\text { Treatment, IU/ml(range) }\end{array}$ & $\begin{array}{c}37(10- \\
231)\end{array}$ & $14(10-31)$ & $54(10-231)$ & - \\
\hline
\end{tabular}

\section{Diagnostic criteria for DTC DMS}

Diagnosis of DMs from DTC depended on Tg, TgAb under T4 withdrawal for 2-3 weeks, ${ }^{131}$ I-WBS combined with SPECT/CT after ${ }^{131}$ I therapy, ${ }^{18} \mathrm{~F}$-FDG PET/CT, CT, magnetic resonance imaging (MRI) or fine needle biopsy results; and was based on the following three criteria: (a) pathological results showed DMs; (b) ${ }^{131}$ I-WBS demonstrated distant lesions with high ${ }^{131}$ I uptake, with at least one imaging method (CT, MRI, or ${ }^{131}$ I-SPECT/CT) showing DMs; or (c) ${ }^{131}$ I-WBS reveals no ${ }^{131}$ I uptake, but the ${ }^{18}$ F-FDG-PET/CT scans are positive for DM lesions with elevated serum Tg.

\section{${ }^{131}$ I empiric treatment}

Each patient stopped taking L-T4 and undertook a low-iodine diet for 2-3 weeks before ${ }^{131}$ I therapy. Subsequently, the patients received oral ${ }^{131} \mathrm{I}$ after routine measurements that included FT3, FT4, TSH, $\mathrm{Tg}$, TgAb, neck ultrasonography (US), and CT scans. The first oral dose of $3.7 \mathrm{GBq}(100 \mathrm{mCi})$ of ${ }^{131} \mathrm{I}$ was administered to ablate thyroid remnants. Oral doses of ${ }^{131} \mathrm{I}$ with standard activities of 5.55-7.4 GBq (150$200 \mathrm{mCi}$ ) were administered for subsequent treatment of DTC DMs. Patients underwent ${ }^{131} \mathrm{I}$-WBS combined with ${ }^{131}$ I-SPECT/CT imaging 3-5 days after ${ }^{131}$ I oral administration. Treatment intervals ranged from 4-6 months; treatments were repeated 1-6 times. Median follow-up period was 1.2 years (range: $0.2-3$ years).

\section{Definition of Radioiodine-Refractory DTC}

According to the 2015 American Thyroid Association management guideline [16], radioiodinerefractory structurally evident DTC in patients with DMs who were under appropriate TSH stimulation and iodine preparation is classified by 4 mechanisms: (i) metastatic lesions do not ever uptake ${ }^{131} \mathrm{I}$ after successful remnant thyroid ablation; (ii) tumor tissue loses the ability to concentrate ${ }^{131}$ I after previous evidence of RAI-avid disease (in the absence of stable iodine contamination), (iii) ${ }^{131}$ I is concentrated in some lesions but not in others; and (iv) metastatic disease progresses despite significant concentration of ${ }^{131}$ I in the course of ${ }^{131}$ I treatment. 


\section{Cellular Physiology Cell Physiol Biochem 2018;48:718-730 and Biochemistry Published $\begin{aligned} & \text { DOI: 10.1159/000491898 } \\ & \text { (c) } 2018 \text { The Author(s). Published by S. Karger AG, Basel } \\ & \text { www.karger.com/cpb }\end{aligned}$ Qiu et al.: Circulating Tumor Cells in DTC}

Evaluation criteria for progression-free survival (PFS)

Progressive disease (PD), stable disease (SD), partial response (PR), and complete response (CR) to ${ }^{131}$ I treatment for DTC lung and bone metastases were evaluated based on the Response Evaluation Criteria in Solid Tumors (RECIST 1.1) [17] and MDA criteria [18]respectively.

RECIST 1.1: complete response (CR), disappearance of all target lesions, any pathological lesions (target or non-target) must have a reduction in short axis to $<10 \mathrm{~mm}$; partial response (PR), $\geq 30 \%$ decrease in the diameters of target lesions; progressive disease (PD), $\geq 20 \%$ increase in the diameters of target lesions, combined with an absolute increase of $\geq 5 \mathrm{~mm}$ in the sum of diameters (the appearance of one or more new lesions was also considered progression); stable disease (SD), neither sufficient shrinkage to qualify for PR nor sufficient increase to qualify for PD.

MDA criteria: 1) CR: complete sclerotic fill-in of lytic lesions on X-ray or CT; normalization of bone density on X-ray or CT; normalization of signal intensity on MRI. 2) PR: development of a sclerotic rim or partial sclerotic fill-in of lytic lesions on X-ray or CT; interval visualization of lesions with sclerotic rims or new sclerotic lesions in the setting of other signs of PR and absence of progressive bony disease; $\geq 50 \%$ decrease in measurable lesions on X-ray, CT, or MRI; $\geq 50 \%$ subjective decrease in the size of ill-defined lesions on X-ray, CT, or MRI. 3) SD: no change; $<25 \%$ increase or $<50 \%$ decrease in size of measurable lesions; $<25 \%$ subjective increase or $<50 \%$ decrease in size of ill-defined lesions; no new bone metastases. 4) PD: $\geq 25 \%$ increase in size of measurable lesions on X-ray, CT, or MRI; $\geq 25 \%$ subjective increase in the size of ill-defined lesions on X-ray, CT, or MRI; new bone metastases.

PFS was measured from the date of baseline blood sample to the date of confirmed clinical progression or death was censored at last follow-up.

\section{Subtraction enrichment of CTCs}

Enrichment of CTCs was performed according to NE-iFISH kit instruction (Majorbio, Shanghai, China) and according to a previously published protocol $[14,15]$. In brief, peripheral blood samples $(7.5 \mathrm{ml})$ were collected into ACD anticoagulant tubes when all patients ceased thyroid hormone medication and began low-iodine diets, more than 2-3 weeks before the first ${ }^{131}$ I therapy. The supernatant was discarded after centrifuging the tubes within 24 hours after sample collection. Samples were transferred to centrifuge tubes containing $3 \mathrm{ml}$ of lymphocyte separation media (Majorbio). After centrifuging for $10 \mathrm{~min}$ at $450 \mathrm{~g}$, the cell suspension was collected from the buffy-coat layer. Immunomagnetic particles conjugated anti-CD45 antibody (Majorbio) were added into the cell suspension, which was incubated at room temperature for $10 \mathrm{~min}$ and then placed on a magnetic stand (Majorbio) until the liquid became clear. The supernatant was pipetted off the magnetic field to remove leukocytes by centrifuging at $900 \mathrm{~g}$ for $5 \mathrm{~min}$.

\section{Identification of aneuploidy CTCS}

The identification of CTCs was performed according to mi-FISH kit instruction (Majorbio). To identify aneuploid CTCs, fluorescence in situ hybridization (FISH) and immunocytochemistry were used in combination. The supernatant was rinsed with wash buffer, and then monoclonal antibody anti-CD45 conjugated to Alexa Fluor 594 (Majorbio) and anti- anti-EpCAM Antibody conjugated to Alexa Fluor 488 (Majorbio) were added before incubation at room temperature for $30 \mathrm{~min}$. The supernatant was rinsed with wash buffer. To the obtained cellular precipitation, we immediately added cell fixatives-1 (Majorbio) before making smears. The cell smears were dried at $32{ }^{\circ} \mathrm{C}$ overnight. We added $200 \mu \mathrm{l}$ of cell fixatives-2 (Majorbio) to the cell smears and let stand for $10 \mathrm{~min}$. After rinsing with wash buffer, the mixture was put into in a $100 \%$ alcohol after washing and let stand for $1 \mathrm{~min}$. After the slide was air-dried, $10 \mu \mathrm{l}$ of probe solution containing fluorescence-labeled alpha-satellite probes for Centromere Probe 8 (CEP8) SpectrumOrange (Vysis, Abbott Laboratories, Abbott Park, IL, USA) was added and then covered with a coverslip and sealed with neutral resin (rubber). The hybridization procedure was as follows: degeneration at $75^{\circ} \mathrm{C}$ for $5 \mathrm{~min}$, followed by hybridization at $37^{\circ} \mathrm{C}$ for 4 hours. After rinsing with PBS, the slides were mounted with mounting medium containing DAPI and photographed with a fluorescence microscope (Zeiss, German). CTCs were confirmed to be negative for CD45 and either positive for EpCAM staining or aneuploidy chromosome 8. CTCs were defined as EpCAM+/CD45-/DAPI+/CEP8 $\geq 2$ or EpCAM-/CD45-/DAPI+/CEP8>2, whereas EpCAM-/ CD45+/DAPI+/CEP8=2 was defined as white blood cells (WBCs) $[14,15]$. All CTC numbers in this paper are the numbers of CTCs counted in 7.5-ml samples of subjects' peripheral venous blood.

\section{KARGER}




\section{Statistical analysis}

Student's $t$-test was used to test for significant differences in numbers of CTCs among the $\mathrm{DM}^{+}$DTC, DM ${ }^{-}$DTC and HC groups. Receiver operating characteristic (ROC) curves were constructed, and area under curve (AUC) was calculated to evaluate specificity and sensitivity of predicting DMs from DTC or RR-DTC. The chisquare test or Fisher's exact test and multivariate logistic regression analyses were used to evaluate CTC numbers with respect to clinicopathological factors. The Kaplan-Meier method was used for PFS analysis; differences in PFS were examined using the log-rank test. Multivariate analysis was performed to assess relationships between PFS and several variables simultaneously using Cox's proportional hazards model. $P<0.05$ was considered significant. MedCalc software version 17.0 (MedCalc, Mariakerke, Belgium) and SPSS17.0 (SPSS Inc., Chicago, IL, USA) were used for statistical analyses.

\section{Results}

Distribution of CTC counts in each classification

The CTC counts for the HC, $\mathrm{DM}^{-}$DTC and DM+ DTC groups are shown in Fig. 1 and Fig. 2a. The CTCs were defined as Ep$\mathrm{CAM}^{+} / \mathrm{CD}_{4} 5^{-} / \mathrm{DAPI}^{+} / \mathrm{CEP} 8 \geq 2$, which weren't be detected in the $7.5 \mathrm{ml}$ blood. The numbers of detected CTCs (per 7.5 $\mathrm{ml}$ blood) in the DTC patients were median: 4; range: 0-72; mean: 7.31, total: 527; and were found in 62 of the 72 patients $(86.1 \%)$. In the $\mathrm{DM}^{+}$DTC group, CTCs were detected in $92.9 \%(39 / 42)$ of patients (mean: 10.69; range: 0-72). In the DM- DTC group, CTCs were in $76.7 \%(23 / 30)$ of patients (mean: 2.6; range: 0-10). In the HC group, CTCs were found in 26.7\% ( $8 / 30)$ of subjects (mean: 0.4; range: $1-3$, including 1 CTC: $n=5 ; 2$ CTCs: $n=1 ; 3$ CTCs: $n=2$ ). Mean CTC numbers were significantly higher in the $\mathrm{DM}^{+} \mathrm{DTC}$ than in the $\mathrm{HC}$
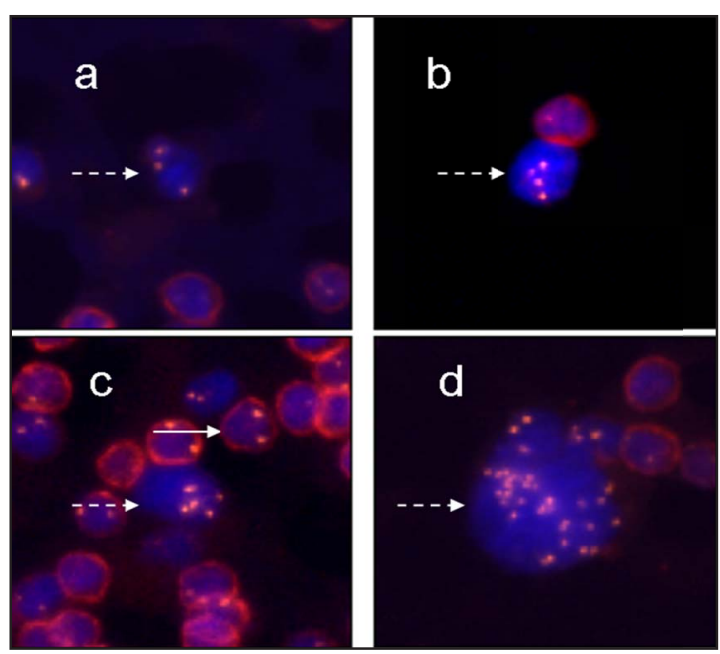

Fig. 1. Identification of CTCs in patients with differentiated thyroid cancer (DTC) by NE-iFISH assay. CTCs were defined as $\mathrm{EpCAM}^{-} / \mathrm{CD}^{2} 5^{-} / \mathrm{DAPI}^{+} /$ CEP8 >2; white blood cells (WBCs) were defined as $\mathrm{EpCAM}^{-} / \mathrm{CD}^{2} 5^{+} / \mathrm{DAPI}^{+} / \mathrm{CEP} 8=2$. a: $\mathrm{EpCAM}^{-} / \mathrm{CD}^{-} 5^{-} /$ $\mathrm{DAPI}^{+} / \mathrm{CEP} 8=3$ (white dotted arrow); b: $\mathrm{EpCAM}^{-}$/ $\mathrm{CD}^{-} 5^{-} / \mathrm{DAPI}^{+} / \mathrm{CEP} 8=4$ (white dotted arrow) c: $\mathrm{EpCAM}^{-} / \mathrm{CD}^{-} 5^{-} / \mathrm{DAPI}^{+} / \mathrm{CEP} 8=5$ (white dotted arrow), $\mathrm{EpCAM}^{-} / \mathrm{CD} 45^{+} / \mathrm{DAPI}^{+} / \mathrm{CEP} 8=2$ (white solid arrow); d: $\mathrm{EpCAM}^{+} / \mathrm{CD}^{-} 5^{-} / \mathrm{DAPI}^{+} / \mathrm{CEP} 8 \geq 5$ (white dotted arrow).
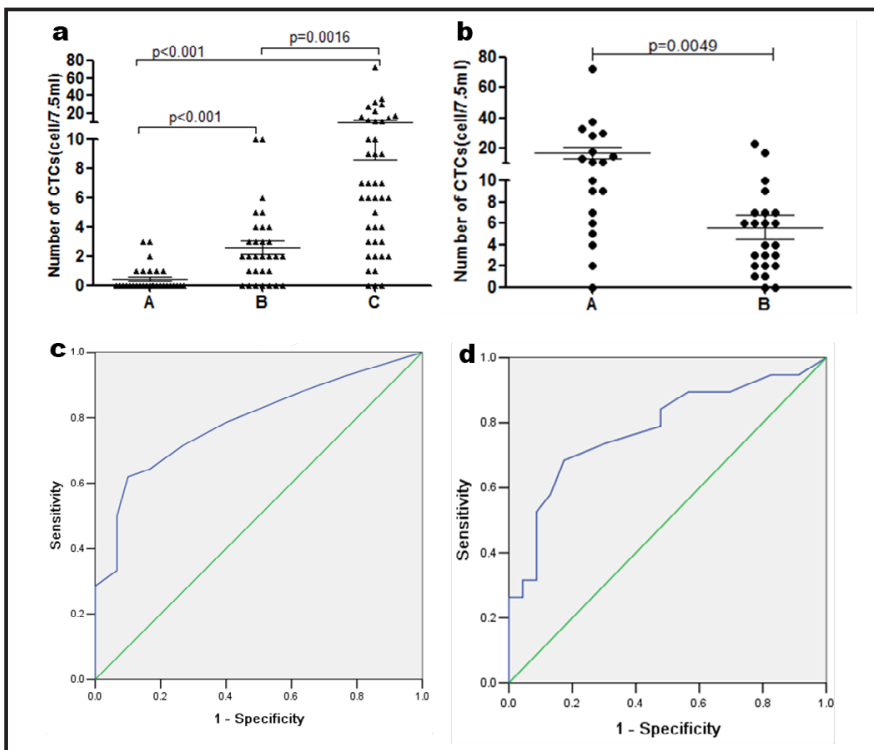

Fig. 2. a: CTC count in healthy controls (A), patients with differentiated thyroid cancer (DTC) without distant metastases (B) and DTC patients with distant metastases (C). b: CTC count in RR-DTC patients (A) and non-RR-DTC patients (B). c: ROC curve shows sensitivity and specificity at 4.5 CTCs in $7.5 \mathrm{ml}$ of blood in predicting distant metastases in patients with DTC. d: ROC curve shows sensitivity and specificity at 6.5 CTCs in $7.5 \mathrm{ml}$ of blood in predicting distant metastases in RR-DTC patients. 


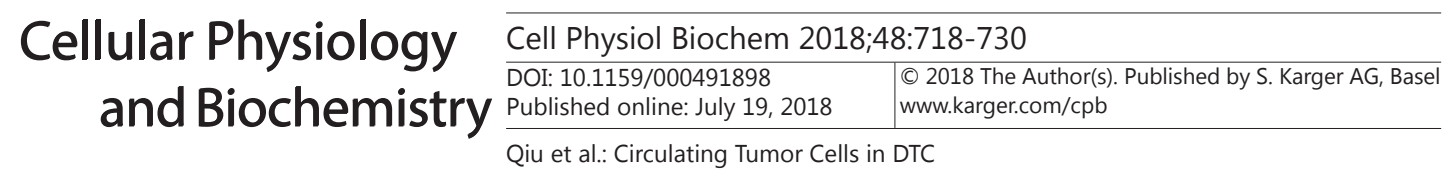

group $(P<0.001)$ and $\mathrm{DM}^{-} \mathrm{DTC}$ group $(P=0.0016)$; and higher in the $\mathrm{DM}^{-} \mathrm{DTC}$ group than in the HC group $(P<0.001)$.

Correlation of CTCs with clinicopathological characteristics between DM+ DTC and DMDTC groups

We plotted a ROC curve to compare the sensitivity and specificity of CTC numbers with respect to $\mathrm{DM}^{+}$DTC and $\mathrm{DM}^{-}$DTC, using 3.5 CTCs (71.4\% sensitive; 73.3\% specific), 4.5 CTCs (64.3\% sensitive; $83.8 \%$ specific) and 5.5 CTCs (61.9\% sensitive; $90 \%$ specific) as possible cut-off values (Youden's index). We therefore defined the cutoff at 4.5 CTCs (AUC: 0.789; 95\% CI: 0.685-0.893; Fig. 2c). In the DM+ DTC group, 27 (64.3\%) had more, and 15 had fewer, than 4.5 CTCs, whereas in the DM- DTC group, 5 (16.7\%) had more CTCs and 25 had fewer $(P<0.001)$. Therefore, CTCs $\geq 5$ was considered predictive of DMs.

Patient age at baseline, sex, DTC pathology, tumor size, extrathyroidal invasion, multifocality and $\mathrm{N}$ stage were not significantly associated with CTCs $\geq 5$. In univariate regression, CTCs $\geq 5$ was significantly associated with $\mathrm{sTg}>200 \mathrm{ng} / \mathrm{ml}$ (odds ratio [OR]: 3.667, 95\% CI: $1.370-9.810$ ) and DM $^{+}$DTC (OR: $0.111,95 \%$ CI: $0.035-0.351$ ) in binary logistic regression, only $\mathrm{DM}^{+}$DTC was independently associated with CTCs $\geq 5(P=0.009$; OR compared with DM- DTC: 0.028 (95\% CI: 0.002-0.403, Table 2).

Table 2. Comparison of Clinical and Pathologic Factors between DTC patients with CTCs $\geq 5 / 7.5 \mathrm{ml}$ and CTCs $<5 / 7.5 \mathrm{ml}$ blood using the Univariate and Multivariate Analysis. Tumor size ( $\mathrm{mm}$ ): maximum diameter of tumor; DTC: differentiated thyroid cancer; DM: distant metastases

\begin{tabular}{|c|c|c|c|c|c|c|c|}
\hline \multirow{2}{*}{ Variations } & \multicolumn{3}{|c|}{ No. of patients } & \multicolumn{2}{|c|}{ Univariate analysis } & \multicolumn{2}{|c|}{ Multivariate analysis } \\
\hline & All & $\mathrm{CTCs} \geq 5$ & CTCs $<5$ & OR(95\%CI) & $\mathrm{P}$ & OR(95\%CI) & $\mathrm{P}$ \\
\hline Sex & & & & & 0.287 & & 0.193 \\
\hline Male & 41 & 16 & 25 & 1 & & 1 & \\
\hline Female & 31 & 16 & 15 & $\begin{array}{c}1.667[0.649- \\
4.281]\end{array}$ & & $\begin{array}{c}2.223[0.667- \\
7.405]\end{array}$ & \\
\hline Age at baseline & & & & & 0.289 & & 0.992 \\
\hline$<45 \mathrm{y}$ & 32 & 12 & 20 & 1 & & 1 & \\
\hline$\geq 45 \mathrm{y}$ & 40 & 20 & 20 & $\begin{array}{c}1.667[0.647- \\
4.296]\end{array}$ & & $\begin{array}{c}1.011[0.304- \\
3.331]\end{array}$ & \\
\hline Pathological of DTC & & & & & 0.464 & & 0.701 \\
\hline FTC & 61 & 26 & 35 & 1 & & 1 & \\
\hline PTC & 11 & 6 & 5 & $\begin{array}{c}1.615[0.444- \\
5.873]\end{array}$ & & $\begin{array}{c}1.415[0.243- \\
8.239]\end{array}$ & \\
\hline $\begin{array}{l}\text { Extrathyroidal } \\
\text { invasion }\end{array}$ & & & & & 0.915 & & 0.359 \\
\hline No & 41 & 18 & 23 & 1 & & 1 & \\
\hline Yes & 31 & 14 & 17 & $\begin{array}{c}1.052[0.412- \\
2.690]\end{array}$ & & $\begin{array}{c}1.747[0.530- \\
5.754]\end{array}$ & \\
\hline Multifocality & & & & & 0.584 & & 0.594 \\
\hline 1 & 54 & 23 & 31 & 1 & & 1 & \\
\hline$>1$ & 18 & 9 & 9 & $\begin{array}{c}1.348[0.462- \\
3.924]\end{array}$ & & $\begin{array}{c}1.453[0.369- \\
5.720]\end{array}$ & \\
\hline Tumor size(mm) & & & & & 0.043 & & 0.485 \\
\hline$\leq 30$ & 41 & 14 & 27 & 1 & & 1 & \\
\hline$>30$ & 31 & 18 & 13 & $\begin{array}{c}2.670[1.020- \\
\quad 6.989]\end{array}$ & & $\begin{array}{c}1.585[0.435- \\
5.773]\end{array}$ & \\
\hline N stage & & & & & 0.792 & & 0.804 \\
\hline N1 & 37 & 17 & 20 & 1 & & 1 & \\
\hline $\mathrm{N} 0, \mathrm{x}$ & 35 & 15 & 20 & $\begin{array}{c}0.882[0.348- \\
2.238]\end{array}$ & & $\begin{array}{c}0.842[0.217- \\
3.266]\end{array}$ & \\
\hline $\mathrm{sTg}(\mathrm{ng} / \mathrm{ml})$ & & & & & 0.008 & & 0.277 \\
\hline$\leq 200$ & 35 & 10 & 25 & 1 & & 1 & \\
\hline$>200$ & 37 & 22 & 15 & $\begin{array}{c}3.667[1.370- \\
9.810]\end{array}$ & & $\begin{array}{c}4.278[0.311- \\
58.86]\end{array}$ & \\
\hline DTC with DM & & & & & $<0.001$ & & 0.009 \\
\hline Yes & 42 & 27 & 15 & 1 & & 1 & \\
\hline No & 30 & 5 & 25 & $\begin{array}{c}0.111[0.035- \\
0.351]\end{array}$ & & $\begin{array}{c}0.028[0.002- \\
0.403]\end{array}$ & \\
\hline
\end{tabular}


Correlation of CTCS with RR-DTC in DTC patients

Clinical characteristics of the DM+ DTC group $(n=42)$ are shown in Table 3 and Table 4. Their median age was 43.2 years (range 12-71 years); they included 17 males and 25 females; 33 had PTC and 11 had FTC; 5 had only bone metastases, 24 had only lung metastases, 11 had synchronous bone and lung metastases; 1 had synchronous bone and brain metastases, and 1 had synchronous bone and kidney metastases.

We classified $19 \mathrm{DM}^{+}$DTC patients as RR-DTC and 23 as non-RR-DTC (2015 ATA guidelines). Mean numbers of CTCs in the RR-DTC group (16.8) were significantly higher than in the non-RR-DTC group (5.60; $P=0.0049$; Fig. 2b).

To determine the CTC count cutoff that would be most indicative of RR-DTC, we tested 4.5 CTCs (sensitivity: 84.2\%; specificity: 52.2\%), 5.5 CTCs (sensitivity: 78.9\%; specificity: 52.2\%) and 6.5 CTCs (sensitivity: 73.7\%; specificity: 69.6\%), and finally used 6.5 CTCs as the cut-off number (AUC=0.781; 95\%CI 0.635-0.928; Fig. 2d). In the DM ${ }^{+}$RR-DTC group $(n=19)$, $14(73.6 \%)$ patients had more CTCs and 5 had fewer than the 6.5 CTC cut-off; whereas in the DM $^{-}$non-RR-DTC group ( $\left.n=23\right), 7$ (30.4\%) had more CTCs and 16 had fewer than the cut-off $(P<0.001)$. Therefore, CTCs $\geq 7$ was considered indicative of RR-DTC.

Univariate analysis of factors considered likely to be associated with RR-DTC (or specifically, CTCs $\geq 7$ ) are shown in Table 4 . Only RR-DTC was significantly associated with CTCs $\geq 7$ ( $P=0.005$; OR compared with non-RR-DTC: $0.156,95 \%$ CI: 0.040-0.605). In multivariate logistic regression analysis, patient age at baseline, sex, DTC pathology, tumor

Table 3. Clinical Data for Each Patient with Distant Metastases from Differentiated Thyroid Cancer. Age *: age at baseline; F: female; M: male, sTg: Stimulated thyroglobulin; FTC: follicular thyroid carcinoma; PTC: papillary thyroid carcinoma; Lungs: multiple lung metastases; bones: multiple bone metastases

\begin{tabular}{|c|c|c|c|c|c|c|c|c|c|c|}
\hline $\begin{array}{l}\text { Patient } \\
\text { number }\end{array}$ & Sex & $\begin{array}{l}\text { Age* }^{*} \\
\text { (years) }\end{array}$ & $\begin{array}{c}\text { Diameter }_{\max } \text { of } \\
\text { primary } \\
\text { tumor }(\mathrm{cm})\end{array}$ & Pathology & $\begin{array}{l}\text { Sites of } \\
\text { DM }\end{array}$ & $\mathrm{sTg}(\mathrm{ng} / \mathrm{ml})$ & $\begin{array}{l}\text { No.of } \\
\text { CTCs }\end{array}$ & $\begin{array}{l}\text { Courses }{ }^{131} \mathrm{I} \\
\text { treatment (n) }\end{array}$ & $\begin{array}{l}\text { Cumulative } \\
\text { 131I activity }\end{array}$ & $\begin{array}{l}\text { Refractory to } \\
\text { radioiodine }\end{array}$ \\
\hline 1 & $\mathrm{~F}$ & 32 & 4.8 & PTC & Lungs & 811.4 & 72 & 5 & 37.0 & Yes \\
\hline 2 & M & 25 & 3.9 & PTC & Lungs & 883 & 37 & 2 & 14.8 & Yes \\
\hline 3 & F & 27 & 3.2 & PTC & $\begin{array}{l}\text { Lungs, } \\
\text { bone }\end{array}$ & 981 & 33 & 2 & 12.95 & Yes \\
\hline 4 & $\mathrm{~F}$ & 56 & 3.5 & PTC & $\begin{array}{l}\text { Bones, } \\
\text { brain }\end{array}$ & 458.4 & 30 & 3 & 22.2 & Yes \\
\hline 5 & M & 28 & 7.0 & PTC & Lungs & 369.7 & 28 & 2 & 11.1 & Yes \\
\hline 6 & M & 23 & 6.1 & PTC & $\begin{array}{l}\text { Lungs, } \\
\text { bones }\end{array}$ & 808 & 23 & 6 & 44.4 & No \\
\hline 7 & $\mathrm{M}$ & 59 & 4.5 & FTC & Bones & 574 & 18 & 2 & 7.4 & Yes \\
\hline 8 & M & 62 & 1.1 & PTC & Bones & 3659 & 17 & 2 & 12.95 & No \\
\hline 9 & M & 36 & 2.1 & PTC & Lungs & 807 & 15 & 3 & 22.2 & Yes \\
\hline 10 & $\mathrm{~F}$ & 59 & 3.2 & FTC & Bones & 519.5 & 13 & 2 & 7.4 & Yes \\
\hline 11 & M & 64 & 3.7 & PTC & Lungs & 1141 & 11 & 1 & 7.4 & Yes \\
\hline 12 & $\mathrm{~F}$ & 45 & 4.0 & FTC & Lungs, & 17221 & 11 & 2 & 11.1 & Yes \\
\hline 13 & M & 42 & 2.8 & FTC & $\begin{array}{l}\text { Bone } \\
\text { Lungs }\end{array}$ & 571.2 & 10 & 4 & 20.35 & Yes \\
\hline 14 & $\mathrm{~F}$ & 43 & 3.2 & PTC & Lungs & 268 & 10 & 3 & 18.5 & No \\
\hline 15 & $\mathrm{M}$ & 71 & 2.1 & PTC & $\begin{array}{l}\text { Lungs, } \\
\text { bones }\end{array}$ & 3023 & 9 & 1 & 14.8 & Yes \\
\hline 16 & M & 31 & 4.2 & PTC & $\begin{array}{l}\text { Lungs, } \\
\text { bones }\end{array}$ & 532.6 & 9 & 2 & 12.95 & Yes \\
\hline 17 & $\mathrm{~F}$ & 34 & 2.5 & PTC & Lungs & 118 & 9 & 4 & 25.9 & No \\
\hline 18 & $\mathrm{~F}$ & 53 & 4.0 & PTC & Lungs & 215.2 & 7 & 1 & 7.4 & Yes \\
\hline 19 & $\mathrm{~F}$ & 66 & 4.5 & PTC & Lungs & 415 & 7 & 2 & 11.1 & No \\
\hline 20 & M & 54 & 2.4 & PTC & Lungs & 85 & 7 & 1 & 7.4 & No \\
\hline 21 & $\mathrm{~F}$ & 12 & 1.8 & PTC & Lungs & 41.4 & 7 & 2 & 11.1 & No \\
\hline 22 & M & 41 & 1.8 & PTC & Lungs & 127 & 6 & 3 & 22.2 & No \\
\hline 23 & M & 29 & 3.2 & PTC & Lungs & 1303 & 6 & 2 & 12.95 & Yes \\
\hline 24 & $\mathrm{~F}$ & 22 & 5.0 & PTC & Lungs & 1523 & 6 & 5 & 35.15 & No \\
\hline 25 & $\mathrm{~F}$ & 69 & 3.8 & PTC & $\begin{array}{l}\text { Lungs, } \\
\text { bones }\end{array}$ & 12785 & 6 & 3 & 22.2 & No \\
\hline 26 & $\mathrm{~F}$ & 62 & 4.3 & FTC & $\begin{array}{l}\text { Lungs, } \\
\text { bones }\end{array}$ & 1578 & 6 & 2 & 14.8 & No \\
\hline 27 & $\mathrm{~F}$ & 29 & 4.0 & FTC & Lungs & 110 & 5 & 5 & 25.9 & Yes \\
\hline 28 & F & 33 & 2.2 & PTC & Lungs & 4186 & 4 & 3 & 16.65 & No \\
\hline 29 & $\mathrm{~F}$ & 66 & 2.8 & PTC & $\begin{array}{l}\text { Lungs, } \\
\text { bones }\end{array}$ & 9676 & 4 & 3 & 22.2 & Yes \\
\hline 30 & $\mathrm{M}$ & 39 & 4.7 & PTC & Lungs & 15060 & 4 & 1 & 7.4 & No \\
\hline 31 & $\mathrm{~F}$ & 45 & 3.2 & FTC & Lungs & 917 & 3 & 2 & 14.8 & No \\
\hline 32 & $\mathrm{~F}$ & 36 & 2.5 & PTC & Lungs & 4673 & 3 & 3 & 22.2 & No \\
\hline 33 & $\mathrm{~F}$ & 33 & 3.2 & PTC & $\begin{array}{l}\text { Lungs, } \\
\text { bone }\end{array}$ & 724 & 3 & 2 & 12.95 & No \\
\hline 34 & $\mathrm{~F}$ & 23 & 2.3 & PTC & $\begin{array}{l}\text { Done } \\
\text { Lungs }\end{array}$ & 899.5 & 2 & 3 & 22.2 & Yes \\
\hline 35 & M & 14 & 3.0 & PTC & Lungs & 5100 & 2 & 4 & 20.35 & No \\
\hline 36 & $\mathrm{~F}$ & 28 & 2.5 & PTC & $\begin{array}{l}\text { Lungs, } \\
\text { bone }\end{array}$ & 105 & 2 & 3 & 22.2 & No \\
\hline 37 & $\mathrm{~F}$ & 63 & 5.0 & FTC & $\begin{array}{l}\text { bones } \\
\text { kidney }\end{array}$ & 2311 & 2 & 6 & 44.4 & No \\
\hline 38 & $\mathrm{~F}$ & 37 & 3.0 & PTC & bones & 3493 & 1 & 6 & 44.4 & No \\
\hline 39 & $\mathrm{~F}$ & 65 & 3.4 & FTC & bones & 611.7 & 1 & 3 & 22.2 & No \\
\hline 40 & $\mathrm{M}$ & 20 & 4.5 & PTC & $\begin{array}{l}\text { Lungs, } \\
\text { bones }\end{array}$ & 1397 & 0 & 3 & 18.5 & Yes \\
\hline 41 & $\mathrm{~F}$ & 60 & 1.1 & PTC & Lungs & 740 & 0 & 4 & 27.75 & No \\
\hline 42 & M & 58 & 3.2 & PTC & Lungs & 497 & 0 & 3 & 16.65 & No \\
\hline
\end{tabular}


Table 4. Comparison of Clinical and Pathologic Factors between Distant Metastatic DTC Patients with CTCs $\geq 7 / 7.5 \mathrm{ml}$ and CTCs $<7 / 7.5 \mathrm{ml}$ using the Univariate and Multivariate Analysis

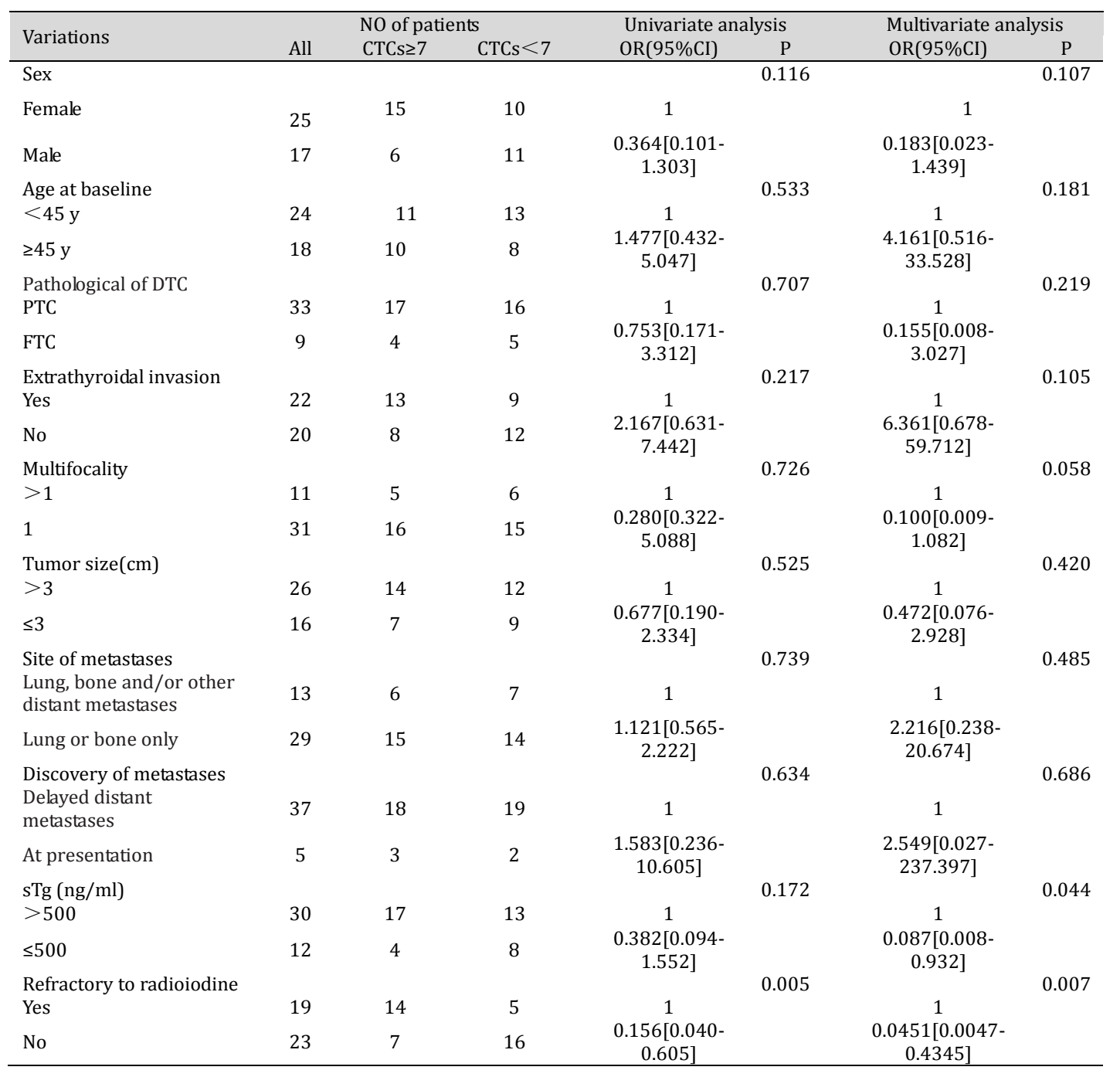

size, extrathyroidal invasion, multifocality, site of metastases, and presence of DM at diagnosis were not associated with CTCs $\geq 7$; whereas CTCs $\geq 7$ was associated with RR-DTC $(P=0.007$; OR: $0.0451,95 \%$ CI: $0.0047-0.4345)$ and sTg level $\leq 500 \mathrm{ng} / \mathrm{ml}(P=0.044 ;$ OR: 0.087, 95\% CI: 0.008-0.932; Table 4).

\section{CTCs correlate with PFS}

Three-year PFS rates and prognostic factors in the DM+ DTC group $(n=42)$ are listed in Table 5 and Table 6. All $42 \mathrm{DM}^{+}$DTC patients had completed at least one course of 131I therapy. At the time of analysis, $19(45.2 \%)$ of the 42 patients had PD, 2 achieved CR (4.8\%), 4 PR (9.5\%), 17 (4.0\%) SD. Median PFS was 1.2 years (range: 0.2-3 years). At the time of follow-up, 4 patients had died of metastatic lesions, and the remaining 38 patients were alive.

In univariate analysis, CTCs $\geq 7$ and RR-DTC were strong predictors of worse 3-year PFS in all $\mathrm{DM}^{+}$DTC patients compared with CTCs $<7$ and non-RR-DTC. In this study, the 3-year PFS rates were CTCs $\geq 7$ : 33.3\%; CTCs <7: 76.2\% (Fig. 3a); non-RR-DTC group: 78.3\%; RRDTC group: $26.3 \%$ (Fig. 3b) . In multivariate Cox regression analyses, PFS was significantly associated with CTCs $\geq 7$ (relative risk [RR]: 5.108, 95\% CI: 1.334-19.550), sTg level $\leq 500$ 
Qiu et al.: Circulating Tumor Cells in DTC

Table 5. Univariate Analysis of Significant Prognostic Factors Influencing Progression-Free Survival (PFS) in 42 Patients with Differentiated Thyroid Cancer and Distant Metastases. PD*: Progressive disease

\begin{tabular}{|c|c|c|c|c|c|}
\hline Variable & $\begin{array}{c}\text { No. of } \\
\text { patients }\end{array}$ & $\begin{array}{c}\text { No. of } \\
\text { PD* }\end{array}$ & $\begin{array}{c}\text { 3-year } \\
\text { PFS rate } \\
(\%)\end{array}$ & $\begin{array}{l}\text { Log-rank } \\
\text { value }\end{array}$ & $\mathrm{P}$ \\
\hline No. of CTCs (cell/7.5ml) & & & & 6.271 & 0.01 \\
\hline$\geq 7$ & 21 & 14 & 33.33 & & \\
\hline$<7$ & 21 & 5 & 76.19 & & \\
\hline Sex & & & & 0.275 & 0.600 \\
\hline Female & 25 & 11 & 56.00 & & \\
\hline Male & 17 & 8 & 52.94 & & \\
\hline Age & & & & 0.595 & 0.441 \\
\hline$<45 \mathrm{y}$ & 24 & 13 & 45.83 & & \\
\hline$\geq 45 \mathrm{y}$ & 18 & 6 & 66.67 & & \\
\hline Pathological of DTC & & & & 0.015 & 0.903 \\
\hline PTC & 33 & 15 & 54.55 & & \\
\hline FTC & 9 & 4 & 55.56 & & \\
\hline Extrathyroidal invasion & & & & 0.669 & 0.413 \\
\hline Yes & 22 & 8 & 63.64 & & \\
\hline No & 20 & 11 & 45.00 & & \\
\hline Multifocality & & & & 0.121 & 0.782 \\
\hline$>1$ & 11 & 4 & 63.64 & & \\
\hline 1 & 31 & 15 & 51.61 & & \\
\hline Tumor size $(\mathrm{cm})$ & & & & 2.455 & 0.117 \\
\hline$>3$ & 26 & 13 & 50.00 & & \\
\hline$\leq 3$ & 16 & 6 & 62.50 & & \\
\hline Site of metastases & & & & 0.001 & 0.972 \\
\hline $\begin{array}{l}\text { Lung, bone and/or other distant } \\
\text { metastases }\end{array}$ & 13 & 5 & 61.54 & & \\
\hline Lung or bone only & 29 & 14 & 51.72 & & \\
\hline Discovery of metastases & & & & 0.228 & 0.634 \\
\hline Delayed distant metastases & 37 & 17 & 54.05 & & \\
\hline At presentation & 5 & 2 & 60.00 & & \\
\hline $\operatorname{sTg}(\mathrm{ng} / \mathrm{ml})$ & & & & 1.859 & 0.173 \\
\hline$>500$ & 30 & 14 & 53.33 & & \\
\hline$\leq 500$ & 12 & 5 & 58.33 & & \\
\hline Refractory to radioiodine & & & & 12.97 & $<0.001$ \\
\hline Yes & 19 & 14 & 26.31 & & \\
\hline No & 23 & 5 & 78.26 & & \\
\hline
\end{tabular}

Table 6. Multivariate Analysis of Prognostic Factors of Progression-Free-Survival from 42 Differentiated Thyroid Cancer Patients with Distant Metastases Using Cox’s Proportional Hazards Model

\begin{tabular}{|c|c|c|c|}
\hline Variable & Risk ratio & $95 \%$ CI & $P$ \\
\hline No. of CTCs (cell/7.5ml) & & & 0.021 \\
\hline$<7$ & 1 & & \\
\hline$\geq 7$ & 5.108 & [1.334-19.550] & \\
\hline Sex & & & 0.400 \\
\hline Female & 1 & & \\
\hline Male & 0.535 & {$[0.125-2.280]$} & \\
\hline Age & & & 0.110 \\
\hline$<45$ y & 1 & & \\
\hline$\geq 45 \mathrm{y}$ & 3.094 & {$[0.779-12.282]$} & \\
\hline Pathological of DTC & & & 0.320 \\
\hline PTC & 1 & & \\
\hline FTC & 0.320 & [0.083-2.243] & \\
\hline Extrathyroidal invasion & & & 0.068 \\
\hline No & 1 & & \\
\hline Yes & 4.725 & [0.901-24.792] & \\
\hline Multifocality & & & 0.112 \\
\hline 1 & 1 & & \\
\hline$>1$ & 3.393 & {$[0.758-15.189]$} & \\
\hline Tumor size $(\mathrm{cm})$ & & & 0.902 \\
\hline$\leq 3$ & 1 & & \\
\hline$>3$ & 1.091 & [0.271-4.393] & \\
\hline Site of metastases & & & 0.555 \\
\hline Lung or bone only & 1 & & \\
\hline Lung, bone and/or other distant metastases & 1.720 & {$[0.287-10-328]$} & \\
\hline Discovery of metastases & & & 0.224 \\
\hline At presentation & 1 & & \\
\hline Delayed distant metastases & 0.271 & [0.033-2.196] & \\
\hline sTg (ng/ml) & & & 0.041 \\
\hline$>500$ & 1 & & \\
\hline$\leq 500$ & 0.216 & [0.050-0.936] & \\
\hline Refractory to radioiodine & & & 0.011 \\
\hline Yes & 1 & & \\
\hline No & 0.093 & {$[0.015-0.575]$} & \\
\hline
\end{tabular}


$\mathrm{ng} / \mathrm{ml}(0.216,95 \% \mathrm{CI}: 0.050-$ $0.936)$ and non-RR-DTC (RR: 0.093, 95\% CI: 0.015-0.575).

\section{Discussion}

Circulating biomarkers
can potentially provide early and minimally invasive diagnoses help assess response to therapy and predict prognosis of cancer patients. Studies on the utility

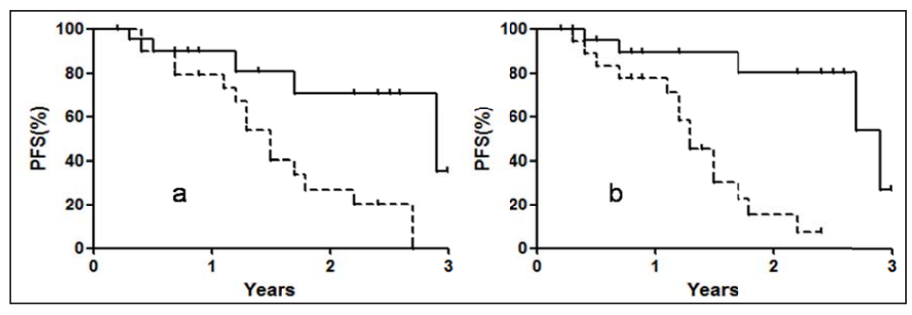

Fig. 3. a: Comparison of PFS curves at CTCs $\geq 7 / 7.5 \mathrm{ml}$ blood (dotted line) and CTCs $<7 / 7.5 \mathrm{ml}$ blood (solid line) in patients with differentiated thyroid cancer (DTC) and distant metastases. b: Comparison of PFS curves between RR (dotted line) and non-RR (solid line) DTC patients with distant metastases. of circulating biomarkers such as cell-free DNA, miRNA, and mRNA as novel biomarkers for various human diseases have increased exponentially in the last decade $[6,19]$. Recent studies have shown CTCs to be prognostic and predictive biomarkers for several solid cancers [20,21]. CTCs are malignant cells that have escaped from primary or metastatic tumor sites [22]. CellSearch is the only FDA-approved technology for CTC detection, which is based on detecting EpCAM expression $[23,24]$. Few studies of the prognostic significance of CTCs from DTC are available. Nonetheless, Xu et al. found that only 1 of 14 patients with DM $^{+}$DTC had detectable CTCs using CellSearch [12]. Therefore, detecting CTCs in DTC patients requires other approaches.

In the present study, we applied a new capture technique (NE-iFISH) to detect DTC CTCs and to assess their relationships with clinicopathological factors, therapeutic repose to ${ }^{131}$ I and prognosis of DTC. Compared with conventional CellSearch, NE-iFISH has demonstrated high sensitivity for CTCs from other cancer types [25, 26].

NE-iFISH has several advantages. On one hand, it applies anti-multiple WBC markers antibodies to ensure both minimum hypotonic injuries to CTCs and maximal removal of WBCs; on the other hand, it can enrich CTCs independently of EpCAM expression and tumor size [27]. We were also able to combine CEP 8, EpCAM, CD 45 and DAPI to detect CTCs. Aneuploidy, which includes both numerical and structural chromosomal abnormalities, is a hallmark of cancer, and might be exploited for CTC detection. Numerical abnormalities of CTCs can be divided into different subtypes, such as triploidy, tetroploidy and multiploidy. Previous studies have shown that CEP 8 reflects numerical chromosomal abnormalities, which have been reported in thyroid cancer, and lung, esophageal, gastric and colon cancers [27-29]. Thus, aneuploidy of CEP 8 examined by CEP8-iFISH can be used to detect CTCs. In our study, of 72 DTC patients, EpCAM ${ }^{-} / \mathrm{CD}^{-} 5^{-} / \mathrm{DAPI}^{+} / \mathrm{CEP} 8>2$ cells were detected in 86.11\% (62/72) patients (mean: 7.14; range: 0-72 CTCs) compared with the HC group, in whom only $26.7 \%(8 / 30)$ subjects had $\mathrm{EpCAM}^{-} / \mathrm{CD}^{-} 5^{-} / \mathrm{DAPI}^{+} / \mathrm{CEP} 8>2$ cells, and none had more than 3 such cells. Obviously, DTC patients had significantly more CTCs than did the HC group. However, EpCAM ${ }^{+} / \mathrm{CD}^{-} 5^{-} / \mathrm{DAPI}^{+} / \mathrm{CEP} 8 \geq 2$ weren't detected in all DTC patients and HC people. Although EpCAM expression has reportedly been found in DTC specimens, those CTCs have not been successfully isolated by means of anti-EpCAM Ab. The reason may be that down-regulated membrane expression and up-regulated nuclear accumulation of EpCAM are associated with EMT during DTC progression and metastasis [13]. This is consistent with the observation of Xu et al. using CellSearch [13].

Patients with breast, prostate, or colorectal cancers with hematogenous metastases reportedly have high incidences of CTCs; CTCs $\geq 5 \mathrm{in} 7.5 \mathrm{ml}$ peripheral venous blood has been widely used as a cut-off to predict DMs from these cancers [23, 30, 31]To predict DMs from DTC we plotted a ROC curve (Yourdon's index), which gave an optimal cutoff for CTCs at 4.5 (as measured by NE-iFISH) which was $64.3 \%$ sensitive and $83.8 \%$ specific for predicting DTC DMs. We therefore used CTCs $\geq 5$ to predict DTC DMs, which is consistent with the above studies. Although we also found that CTCs $\geq 5$ were associated with sTg level $\geq 200 \mathrm{ng} / \mathrm{ml}$ in univariate analysis, in multivariate analysis, only DM+ DTC was associated with CTCs $\geq 5$. 
For RR-DTC patients, ${ }^{131}$ I therapy has very limited benefits. Such patients should not undergo unnecessary ${ }^{131}$ I treatment, which would needlessly expose them to the risk of high serum TSH stimulation after thyroxin withdrawal. Identification of accurate predictive biomarkers is critical to develop novel ${ }^{131}$ I therapeutic strategies. Specifically, noninvasive biomarkers to detect RR-DTC patients are urgently needed before ${ }^{131}$ I therapy. However, circulating tumor biomarkers that can predict response to ${ }^{131}$ I therapy in patients with $\mathrm{DM}^{+}$DTC have not been available. Only our previous study has shown that four circulating long non-coding RNAs have potential utility as diagnostic markers for non- ${ }^{131}{ }^{1}$-avid lung metastases from DTC [6]. In a review of CTCs, only Winkens et al. reported that ${ }^{131}{ }^{11}$ therapy could decrease the number of circulating epithelial cells in the DTC patients [32].

To our knowledge, the present study is the first in which CTCs have been analyzed or compared between non-RR-DTC and RR-DTC patients with DMs. We compared numbers of CTCs between non-RR-DTC and RR-DTC patients using ROC curves and observed whether CTC numbers could predict DM+ RR-DTC. Our study found that the optimal cutoff for CTCs was 6.5 , which was $73.7 \%$ sensitive and $69.6 \%$ specific in predicting $\mathrm{DM}^{+} \mathrm{RR}$-DTC. Therefore, CTCs in $7.5 \mathrm{ml}$ blood serve as a predictor of $\mathrm{DM}^{+} \mathrm{RR}$-DTC. Univariate and multivariate analyses associated CTCs $\geq 7$ in $7.5 \mathrm{ml}$ blood with $\mathrm{DM}^{+}$RR-DTC, and (in multivariate analysis only) with sTg level $\geq 500 \mathrm{ng} / \mathrm{ml}$.

Radioiodine-refractory character is associated with poor outcome in $\mathrm{DM}^{+} \mathrm{DTC}$. Durante et al. reported that the 10 -year survival rate can be $56 \%$ in patients with intense radioiodine accumulation, but as low as $10 \%$ in those who lose radio-iodine avidity [5]. Previously our group showed that DTC patients with non- ${ }^{131}$ I-avid disease had a 10 -year survival rate of $38.1 \%$ compared with $69.2 \%$ for those with ${ }^{131}$ I-avid metastases [2]. As CTCs $\geq 7$ was associated with $\mathrm{DM}^{+}$RR-DTC, we speculate that CTCs $\geq 7$ may also correlate with DM $^{+}$DTC prognosis and progression. Nevertheless, due to short follow-up times in our study (median: 1.2 years, range: $0.2-3$ years), we did not evaluate overall survival, and only analyzed PFS of $\mathrm{DM}^{+}$DTC patients. In view of this, we compared 3-year PFS rates between non-RR-DTC and RR-DTC patients and found that CTCs $\geq 7$ was significantly associated with lower 3-year PFS than CTCs $<7$ (33.3\% vs 76.2\%). Multivariate Cox-regression analyses confirmed that CTC $\geq 7$ is a strong independent predictor of $\mathrm{DM}^{+} \mathrm{RR}-\mathrm{DTC}$.

This study had some limitations. First, the sample size was relatively small, especially for $\mathrm{DM}^{+}$DTC patients. Second, dynamic monitoring of CTCs wasn't performed in the course of ${ }^{131}$ I treatment; which may have missed some measurement deviation. Third, overall survival wasn't evaluated in these DM+ DTC patients because of short follow-up time. Fourth, as our center specializes in ${ }^{131}$ I treatment for DTC patients, primary thyroid surgeries often occurred at other institutions. Therefore, N stages for 16 DTC patients were unclear for us. We also didn't compare sensitivity and specificity of the CTC detection between NE-iFISH and CellSearch technology in these patients.

\section{Conclusion}

For the first time, we have developed a strategy to identify CTCs in DTC patients using NE-iFISH technology. The CTC detection rate was $86.1 \%$ in our DTC patients; CTCs $\geqslant 5$ in 7.5 $\mathrm{ml}$ blood is correlated with $\mathrm{DM}^{+}$DTC (sensitivity: 64.3\%; specificity: 83.8\%). Further, CTCs $\geqslant 7$ may predict DM+ RR-DTC (sensitivity: 73.7\%; specificity $69.6 \%$ ), and is associated with worse prognosis in $\mathrm{DM}^{+}$DTC. We found that assessing CTCs can help predict metastasis, response to ${ }^{131}$ I treatment and prognosis in DTC patients. However, our results need further validation in a larger study.

\section{Acknowledgements}

The authors thank Shanghai Meiji Bio-tech Inc. for their technical support in the CTCs detection and thank Marla Brunker, from Liwen Bianji, Edanz Group China (www.liwenbianji. $\mathrm{cn} / \mathrm{ac}$ ), for polishing the English text of a draft of this manuscript. This study was sponsored 


\section{Cellular Physiology Cell Physiol Biochem 2018;48:718-730

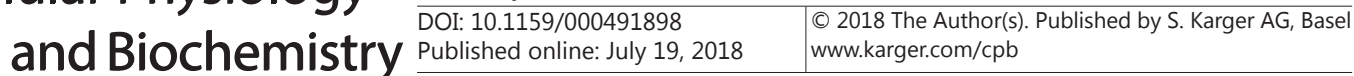 \\ Qiu et al.: Circulating Tumor Cells in DTC}

by the National Natural Science Foundation of China (No: 81771865, 81271611), Shanghai Outstanding Youth Doctor Training Program and Shanghai Key Discipline of Medical Imaging (NO: 2017ZZ02005).

\section{Disclosure Statement}

The authors have declared that no competing interest existed.

\section{References}

-1 Miller KD, Siegel RL, Lin CC, Mariotto AB, Kramer JL, Rowland JH, Stein KD, Alteri R, Jemal A: Cancer treatment and survivorship statistics, 2016. CA Cancer J Clin 2016;66:271-289.

-2 Qiu ZL, Song HJ, Xu YH, Luo QY: Efficacy and survival analysis of 131I therapy for bone metastases from differentiated thyroid cancer. J Clin Endocrinol Metab 2011;96:3078-3086.

3 Song HJ, Qiu ZL, Shen CT, Wei WJ, Luo QY: Pulmonary metastases in differentiated thyroid cancer: efficacy of radioiodine therapy and prognostic factors. Eur J Endocrinol 2015;173:399-408.

4 Casara D, Rubello D, Saladini G, Masarotto G, Favero A, Girelli ME, Busnardo B: Different features of pulmonary metastases in differentiated thyroid cancer: natural history and multivariate statistical analysis of prognostic variables. J Nucl Med 1993;34:1626-1631.

5 Durante C, Haddy N, Baudin E, Leboulleux S, Hartl D, Travagli JP, Caillou B, Ricard M, Lumbroso JD, De Vathaire F, Schlumberger M: Long-term outcome of 444 patients with distant metastases from papillary and follicular thyroid carcinoma: benefits and limits of radioiodine therapy. J Clin Endocrinol Metab 2006;91:2892-2899.

6 Qiu ZL, Shen CT, Sun ZK, Wei WJ, Zhang XY, Song HJ, Luo QY: Circulating Long Non-Coding RNAs Act as Biomarkers for Predicting 131I Uptake and Mortality in Papillary Thyroid Cancer Patients with Lung Metastases. Cell Physiol Biochem 2016;40:1377-1390.

7 Pacini F, Capezzone M, Elisei R, Ceccarelli C, Taddei D, Pinchera A: Diagnostic 131-iodine whole-body scan may be avoided in thyroid cancer patients who have undetectable stimulated serum Tg levels after initial treatment. J Clin Endocrinol Metab 2002;87:1499-1501.

-8 Zhao CL, Qiu ZL, Chen LB, Yuan ZB, Luo QY: Sustained and diffuse 131I avid bone metastases with low thyroglobulin levels in a patient with papillary thyroid carcinoma. Clin Nucl Med 2013;38:375-377.

-9 Wassermann J, Bernier MO, Spano JP, Lepoutre-Lussey C, Buffet C, Simon JM, Menegaux F, Tissier F, Leban M, Leenhardt L: Outcomes and Prognostic Factors in Radioiodine Refractory Differentiated Thyroid Carcinomas. Oncologist 2016;21:50-58.

10 Jia S, Zhang R, Li Z, Li J: Clinical and biological significance of circulating tumor cells, circulating tumor DNA, and exosomes as biomarkers in colorectal cancer. Oncotarget 2017;8:55632-55645.

11 Tang Y, Qiao G, Xu E, Xuan Y, Liao M, Yin G: Biomarkers for early diagnosis, prognosis, prediction, and recurrence monitoring of non-small cell lung cancer. Onco Targets Ther 2017; 10:4527-4534.

12 Thiery JP, Acloque H, Huang RY, Nieto MA: Epithelial-mesenchymal transitions in development and disease. Cell 2009;139:871-890.

-13 Xu JY, Handy B, Michaelis CL, Waguespack SG, Hu MI, Busaidy N, Jimenez C, Cabanillas ME, Fritsche HA, Jr., Cote GJ, Sherman SI: Detection and Prognostic Significance of Circulating Tumor Cells in Patients With Metastatic Thyroid Cancer. J Clin Endocrinol Metab 2016;101:4461-4467.

14 Xu Y, Qin T, Li J, Wang X, Gao C, Xu C, Hao J, Liu J, Gao S, Ren H: Detection of Circulating Tumor Cells Using Negative Enrichment Immunofluorescence and an In Situ Hybridization System in Pancreatic Cancer. Int J Mol Sci 2017;18:

15 Garcia SA, Weitz J, Scholch S: Circulating Tumor Cells. Methods Mol Biol 2018;1692:213-219.

-16 Haugen BR, Alexander EK, Bible KC, Doherty GM, Mandel SJ, Nikiforov YE, Pacini F, Randolph GW, Sawka AM, Schlumberger M, Schuff KG, Sherman SI, Sosa JA, Steward DL, Tuttle RM, Wartofsky L: 2015 American Thyroid Association Management Guidelines for Adult Patients with Thyroid Nodules and Differentiated Thyroid Cancer: The American Thyroid Association Guidelines Task Force on Thyroid Nodules and Differentiated Thyroid Cancer. Thyroid 2016;26:1-133. 


\section{Cellular Physiology Cell Physiol Biochem 2018;48:718-730 \begin{tabular}{l|l} 
DOI: 10.1159/000491898 & $\begin{array}{l}\text { O 2018 The Author(s). Published by S. Karger AG, Basel } \\
\text { www.karger.com/cpb }\end{array}$ \\
\hline
\end{tabular} \\ Qiu et al.: Circulating Tumor Cells in DTC}

17 Nishino M, Jagannathan JP, Ramaiya NH, Van den Abbeele AD: Revised RECIST guideline version 1.1: What oncologists want to know and what radiologists need to know. AJR Am J Roentgenol 2010;195:281-289.

18 Costelloe CM, Chuang HH, Madewell JE, Ueno NT: Cancer Response Criteria and Bone Metastases: RECIST 1.1, MDA and PERCIST. J Cancer 2010;1:80-92.

19 Crowley E, Di Nicolantonio F, Loupakis F, Bardelli A: Liquid biopsy: monitoring cancer-genetics in the blood. Nat Rev Clin Oncol 2013;10:472-484.

20 Okubo K, Uenosono Y, Arigami T, Mataki Y, Matsushita D, Yanagita S, Kurahara H, Sakoda M, Kijima Y, Maemura K, Natsugoe S: Clinical impact of circulating tumor cells and therapy response in pancreatic cancer. Eur J Surg Oncol 2017;43:1050-1055.

-21 Sun T, Zou K, Yuan Z, Yang C, Lin X, Xiong B: Clinicopathological and prognostic significance of circulating tumor cells in patients with head and neck cancer: a meta-analysis. Onco Targets Ther 2017;10:3907-3916.

-22 Cristofanilli M, Budd GT, Ellis MJ, Stopeck A, Matera J, Miller MC, Reuben JM, Doyle GV, Allard WJ, Terstappen LW, Hayes DF: Circulating tumor cells, disease progression, and survival in metastatic breast cancer. N Engl J Med 2004;351:781-791.

23 Cristofanilli M, Hayes DF, Budd GT, Ellis MJ, Stopeck A, Reuben JM, Doyle GV, Matera J, Allard WJ, Miller MC, Fritsche HA, Hortobagyi GN, Terstappen LW: Circulating tumor cells: a novel prognostic factor for newly diagnosed metastatic breast cancer. J Clin Oncol 2005;23:1420-1430.

-24 Cohen SJ, Punt CJ, Iannotti N, Saidman BH, Sabbath KD, Gabrail NY, Picus J, Morse M, Mitchell E, Miller MC, Doyle GV, Tissing H, Terstappen LW, Meropol NJ: Relationship of circulating tumor cells to tumor response, progression-free survival, and overall survival in patients with metastatic colorectal cancer. J Clin Oncol 2008;26:3213-3221.

25 Li Y, Zhang X, Ge S, Gao J, Gong J, Lu M, Zhang Q, Cao Y, Wang DD, Lin PP, Shen L: Clinical significance of phenotyping and karyotyping of circulating tumor cells in patients with advanced gastric cancer. Oncotarget 2014;5:6594-6602.

-26 Wu W, Zhang Z, Gao XH, Shen Z, Jing Y, Lu H, Li H, Yang X, Cui X, Li Y, Lou Z, Liu P, Zhang C, Zhang W: Clinical significance of detecting circulating tumor cells in colorectal cancer using subtraction enrichment and immunostaining-fluorescence in situ hybridization (SE-iFISH). Oncotarget 2017;8:21639-21649.

-27 Lin PP: Integrated EpCAM-independent subtraction enrichment and iFISH strategies to detect and classify disseminated and circulating tumors cells. Clin Transl Med 2015;4:38.

28 Cipollini M, Figlioli G, Garritano S, Bramante S, Maiorano L, Gnudi F, Cecchini A, De Paola F, Damicis L, Frixa T, Landi D, Cancemi L, De Santi C, Melaiu O, Foddis R, Cristaudo A, Bonotti A, Romei C, Elisei R, Pellegrini G, Barale R, Gemignani F, Landi S: Risk of differentiated thyroid carcinoma and polymorphisms within the susceptibility cancer region 8q24. Cancer Epidemiol Biomarkers Prev 2013;22:2121-2125.

-29 Zhu M, Wen X, Liu X, Wang Y, Liang C, Tu J: Association between 8q24 rs6983267 polymorphism and cancer susceptibility: a meta-analysis involving 170, 737 subjects. Oncotarget 2017;8:57421-57439.

-30 Bidard FC, Peeters DJ, Fehm T, Nole F, Gisbert-Criado R, Mavroudis D, Grisanti S, Generali D, Garcia-Saenz JA, Stebbing J, Caldas C, Gazzaniga P, Manso L, Zamarchi R, de Lascoiti AF, De Mattos-Arruda L, Ignatiadis M, Lebofsky R, van Laere SJ, Meier-Stiegen F, Sandri MT, Vidal-Martinez J, Politaki E, Consoli F, Bottini A, Diaz-Rubio E, Krell J, Dawson SJ, Raimondi C, Rutten A, Janni W, Munzone E, Caranana V, Agelaki S, Almici C, Dirix L, Solomayer EF, Zorzino L, Johannes H, Reis-Filho JS, Pantel K, Pierga JY, Michiels S: Clinical validity of circulating tumour cells in patients with metastatic breast cancer: a pooled analysis of individual patient data. Lancet Oncol 2014;15:406-414.

-31 Krebs MG, Sloane R, Priest L, Lancashire L, Hou JM, Greystoke A, Ward TH, Ferraldeschi R, Hughes A, Clack G, Ranson M, Dive C, Blackhall FH: Evaluation and prognostic significance of circulating tumor cells in patients with non-small-cell lung cancer. J Clin Oncol 2011;29:1556-1563.

-32 Winkens T, Pachmann K, Freesmeyer M: Circulating epithelial cells in patients with thyroid carcinoma. Can they be identified in the blood? Nuklearmedizin 2013;52:7-13. 